\title{
Actualidad
}

\section{LUPUS ERITEMATOSO GENERALIZADO}

\author{
Drs. JOSE BAUZA y RAUL HERNANDFZ \\ Hospital "Roberto del Ria".
}

Grande ha sido el progreso en el conocimiento de esta enfermedad desde que Casenave y Schedel en 1833 describieron sus lesiones cutáneas con el nombre de eritema centrífugo, hasta nuestros días con los trabajos de Baehr, Klemperer y Schiffrin y su concepto sobre las enfermedades del mesenquima y, por i]timo, con la publicación de Hargraves y col. en 1948 en que describen el fenómeno de las células del lupus eritematoso, haciendo posible el diagnóstico con una precisión que linda en la especificidad. Sin embargo, hasta la fecha se desconoce la etiología de esta afección.

Aunque se puede afirmar que esta enfermedad predomina en la segunda y tercera décadas de la vida, no son tan excepcionales los casos en otras edades $\mathrm{y}$, en lo que a la infancia se refiere, los datos para indicar su frecuencia son insuficientes y aunque se considera como muy rara, estimamos que es algo más frecuente de lo que comúnmente se cree y que su rareza está condicionada en gran parte por su desccnocimiento por parte de los pediatras. Desde que uno de nosotros en Junio de 1953 presentó el primer caso de lupus eritematoso generalizado a la Sociedad Chilena de Pediatría, hemos encontrado 2 casos más, lo que demuestra que el conocimiento del cuadro clínico, con la ayuda diagnóstica del laboratorio, nos permitirá en el futuro conocer la verdadera incidencia de ella en la infancia.

Se la podría definir como una enfermedad general de fisonomía infecciosa y de curso variable: agudo, subagudo o crónico, con remisiones y exacerbaciones espontáneas, que prefiere la edad juvenil y el sexo femenino y que sus manifestaciones pueden ocupar una amplia gama de la patología, no quedando órgano ni sistema que no sea comprometido, lo que está en relación con que su lesión principal reside en el tejido conjuntivo, su terminación es generalimente fatal y sólo la cortisona o el ACTH pueden modificar favorablemente su curso.

Debe pensarse en ella ante todo cuadro de tipo infeccioso crónico en que el diagnóstico no sea claro, sin esperar la aparición de las manifestaciones cutáneas que pueden ser tardías.

La sintomatología es abigarrada. Desde luego, hay síntomas generales, que $\mathrm{Du}$ bois llama catabólicos, como fiebre, enflaquecimiento, malestar general, etc. La curva térmica no ofrece caracteres especiales y puede adoptar las formas más variadas, simulando cualquier enfermedad febril.

Las lesiones de la piel aparecen en la gran mayoría de los casos, pero no son manifestaciones constantes, necesarias, ni uniformes y en ocasiones la forma discoídea crónica localizada, con mativo de ciertas injurias (Iuz ultravioleta, por ejemplo) puede transformarse en la forma generalizada. Agregaremos que puede aparecer una enorme variedad de exantemas simultánea o sucesivamente. Los púrpuras, de tipo trombopénico, pueden ser las primeras manifestaciones al comienzo de la afección y a veces dominan la escena.

La alopecía es frecuente y la hemos visto en dos de nuestros tres casos.

Los síntomas artríticos, para la mayoría de los autores, son frecuentes e im- 
portantes. En nuestros casos, las manifestaciones de tumefacción articular han sido leves y pasajeras.

Los derrames pleurales son frecuentes $\mathrm{y}$ a veces se acompañan de derrames pericardiacos y de ascitis.

Los sintomas gastrointestinales están representados por inapetencia, náuseas, vómitos y en ocasiones diarrea, que puede ser muy rebelde.

Los síntomas renales son: albuminuria, hematuria y manifestaciones de falla renal progresiva, de mal pronóstico y acompañada de hipertensión.

En la mitad de los casos hay hépato y esplenomegalia y macropoliadenia generalizada.

En algunas ocasiones hay lesiones vasculares focales, que pueden dar lugar a síntomas por parte del sistema nervioso central, como crisis epileptiformes.

Esta lista de sus manifestaciones clínicas no es exaustiva, ya que podríamos agregar tambièn el posible compromiso del pulmón, del endocardio (Síndrome de Libman Sachs), de las arterias (Sindrome de Raynaud), tumefaccion parotidea crónica, anemia, trombopenia, etc.

Para terminar recordaremos que Dubois, divide en 4 grandes grupos las manifestaciones fundamentales del cuadro clínico:

$1^{*}$ Síntomas catabólicos: fiebre, enflaquecimiento, caquexia.

2". Lesiones del tejido conjuntivo: poliserositis (pleuresia, pericarditis, ascitis, artritisi.

3. Lesjones vasculares; de la piel, del fondo del ojo, súndrome de Raynaud; y

$4{ }^{9}$ Depresión de la sangre periférica: anemia, leucopenia, trombopenia.

En las formas con manifestaciones cutáneas típicas, el diagnóstico es sencillo; pero, como ya lo señalamos, estas pueden faltar durante todo el curso o parte de la enfermedad. Por lo tanto, esta afección debe tenerse presente en el diagnóstico diferencial de todo cuadro infeccioso indeterminado, como también en el de aquellas manifestaciones que son frecuentes en el Iupus eritematoso y cuya etiología no aparezca clara, como por ejemplo: artritis reumatoídea, enfermedad reumática de evolución atípica, epilepsia, corea atipica, anemia hemolitica adquirida, leucopenia, síndromes purpúricos, nefritis crónica, endocarditis bacteriana. manifestaciones alérgicas, etc., en particular cuando estas afecciones se acompañan de una sedimentación persistentemente elevada.

En el diagnóstico del lupus eritematoso, el laboratorio brinda una ayuda indispensable. La más importante alteración biaquimica es la hiperglobulinemia; según Gold y Gowing, debe dudarse del diagnóstico en su ausencia. Esta se refleja en otras manifestaciones como son: la alta velocidad de sedimentación y las falsas reacciones positivas de Wassermann y Kahn; también el test de Coombs puede ser positivo y formarse gran cantidad de anticuerpos después de transfusiones. El hemograma revela: anemia, trombopenia y Jeucopenia, esta última de gran importancia diagnóstica.

La presencia de células del lupus eritematoso permite confirmar el diagnostico, pero su ausencia no lo excluye. No puede considerarse a estas células como especificas, puesto que se las ha encontrado en otros cuadros, como ser manifestaciones cutáneas alérgicas después de la administración de penicilina y sulfamidados. Las células del lupus eritematoso son leucocitos polinucleares con una masa amorfa incluida en su protoplasma, que puede ocuparlo totalmente, rechazando el núcleo hacia la periferia. Este aspecto seria el resultado de la fagocitosis por un polinuclear neutrófilo de restos nucleares provenientes de la lisis de otros leucocitos. Es de advertir que este fenómeno se praduce exclusivamente "in vitro" y necesita de cierto tiempo para que alcance toda su intensidad. Para su investigación se usa la llamada "Técnica de las 2 horas", que consiste en buscar estas células en el concentrado proveniente de la expresión del coágulo resultante de $15 \mathrm{cc}$. de sangre que se ha dejado coagular espontánea. mente a la temperatura ambiente por espacio de 2 horas. Las alteraciones nucleares de los leucocitos que son fagocitados, están en relación con la despolimerización del ácido desoxiribonucleico, que es el fenómeno celular fundamental en el lupus eritematoso, el cual no es el resultado del aumento de la desoxiribonucleasa, sino la consecuencia de la carencia del inhibidor intracelular de esta enzima.

La manifestación anátomo-patológica mis importanté en esta enfermedad es la degeneración fibrinoídea de las fibras colágenas, seguida de hialinización y esclerosis. Puede haber proliferación fibroblástica, necrosis de las células del tejido con- 
juntivo e infiltración inflamatoria con células redondas de los tejidos necróticos o degenerados.

La etiología es desconocida. Hoy día se acepta que tanto las formas localizadas como las generalizadas, no son sino grados de la misma enfermedad o, por lo menos, que ambas formas están íntimamente ligadas, pues se ha visto que también en las formas localizadas existen las mismas alteraciones bioquímicas, como son: la hiperglobulinemia y la alta velocidad de sedimentación de los eritrocitos. Según Ehrich el lupus eritematoso debe incluirse en el grupo de las enfermedades denominadas por él disgamaglobulinemias, porque en ellas la gama-globulina difiere inmunológicamente de la gama-globulina normal, lo que condicionaría la aparición del fenómeno de las células del lupus.

El interés por esta enfermedad, además de su importancia teórica, se ha intensificado al conocerse que su curso puede ser favorablemente influenciado por la Cortiscna y el ACTH. Con estas hormonas desaparece la fiebre, la anorexia y el malestar general, a las pocas horas de iniciado el tratamiento y las artritis, las manifestaciones cutáneas y la linfoadenopatía, entre 1 y 3 semanas. Las dosis de Cortisona empleadas varian entre 100 y 200 milígramos diarios durante las primeras semanas, para dar una dosis de mantención de 50 mjlígramos diarios por 8 a 30 meses. A pesar de la mejoría clínica, el fenómeno de las células del lupus persiste. No hay que olvidar que, de acuerdo con Ia experiencia de Dubois, este tratamiento efectuado en los casos leves puede inhibir la posibilidad de remisiones espontáneas.

También se ha ensayado la mostaza nitrogenada y el TEM con resultados comparables a los de la cortisona; no obstante, debe preferirse esta última por ser más fácil de obtener y menos peligrosa para el paciente.

\section{BIBLIOGRAFÍA}

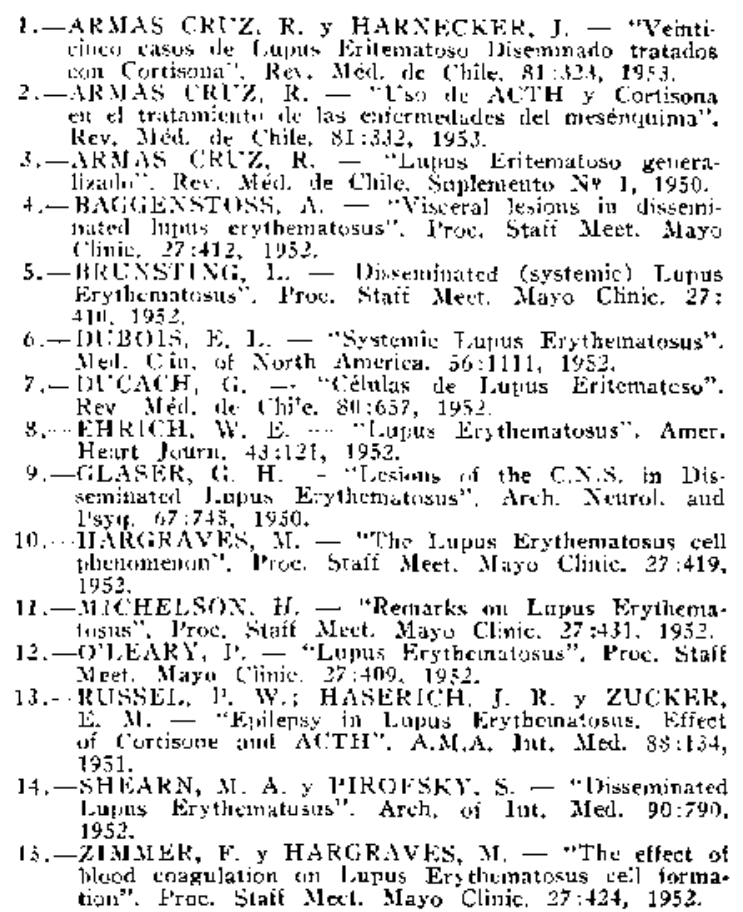

